\title{
Perfusion of the deep inferior epigastric perforator flap measured by laser Doppler imager
}

Citation for published version (APA):

van den Heuvel, M. G. W., Mermans, J. F., Ambergen, A. W., \& van der Hulst, R. R. W. J. (2011).

Perfusion of the deep inferior epigastric perforator flap measured by laser Doppler imager. Annals of Plastic Surgery, 66(6), 648-653. https://doi.org/10.1097/SAP.0b013e3181e37bc8

Document status and date:

Published: 01/01/2011

DOI:

10.1097/SAP.0b013e3181e37bc8

Document Version:

Publisher's PDF, also known as Version of record

\section{Please check the document version of this publication:}

- A submitted manuscript is the version of the article upon submission and before peer-review. There can be important differences between the submitted version and the official published version of record. People interested in the research are advised to contact the author for the final version of the publication, or visit the DOI to the publisher's website.

- The final author version and the galley proof are versions of the publication after peer review.

- The final published version features the final layout of the paper including the volume, issue and page numbers.

Link to publication

\footnotetext{
General rights rights.

- You may freely distribute the URL identifying the publication in the public portal. please follow below link for the End User Agreement:

www.umlib.nl/taverne-license

Take down policy

If you believe that this document breaches copyright please contact us at:

repository@maastrichtuniversity.nl

providing details and we will investigate your claim.
}

Copyright and moral rights for the publications made accessible in the public portal are retained by the authors and/or other copyright owners and it is a condition of accessing publications that users recognise and abide by the legal requirements associated with these

- Users may download and print one copy of any publication from the public portal for the purpose of private study or research.

- You may not further distribute the material or use it for any profit-making activity or commercial gain

If the publication is distributed under the terms of Article $25 \mathrm{fa}$ of the Dutch Copyright Act, indicated by the "Taverne" license above, 


\title{
Perfusion of the Deep Inferior Epigastric Perforator Flap Measured by Laser Doppler Imager
}

\author{
Marieke G. W. van den Heuvel, MD, * Joline F. Mermans, * Anton W. Ambergen, PhD, $\dagger$ \\ and René R. W. J. van der Hulst, MD, PhD*
}

\begin{abstract}
Background: During surgery, circulation changes in the deep inferior epigastric perforator free flap (DIEP). Although blood flow is an important parameter for surgical outcome, little research has been performed on this topic, especially during the process of transplantation. This study examined the pattern of perfusion of DIEP flaps over time.

Methods: In all, 16 flaps were studied in 14 DIEP patients. Flap perfusion was measured with the laser Doppler imager at 4 different time pointsbefore, during, and after surgery.

Results: Both central and peripheral perfusion did not alter after dissection, when blood supply became restricted to the abdominal vascular pedicle. After transplantation, blood flow was higher in the central part of the flap compared with the peripheral border. Central flow increased after transplantation, compared with measurements before and during surgery. Peripheral flow, however, decreased after transplantation.

Conclusions: Surprisingly, flap perfusion did not alter after dissection. It only changed after flap transplantation, when central blood flow increased and peripheral flow decreased.
\end{abstract}

Key Words: (free) flap, laser Doppler imager, blood flow, perfusion (Ann Plast Surg 2011;66: 648-653)

\section{$T$} e "deep inferior epigastric perforator" (DIEP) free flap is often used in a reconstructive operation in which abdominal tissue is used to reconstruct the breast after a mastectomy or breast amputation. During this operation, blood flow in the free flap changes. Circulation in the flap becomes restricted to 1 perforating artery and 1 vein. Blood flow in a free flap is an important parameter for the outcome of flap surgery. In case of impaired blood flow, flap failure or other complications may occur. ${ }^{1}$ However, little research has been performed on perfusion of free flaps, especially during the process of transplantation. There are many studies describing measurements with Doppler or laser Doppler flowmetry (LDF), but they all are focused on postoperative monitoring of free flaps. Only few studies determined blood flow in different areas of flaps before, during, and after surgery. ${ }^{2}$

Received September 10, 2009, and accepted for publication, after revision, April $18,2010$.

From the Departments of *Plastic, Reconstructive, and Hand Surgery, and $\uparrow$ Methodology and Statistics, Maastricht University Medical Centre, Maastricht, The Netherlands.

Presented at the spring congress of the Dutch Society of Plastic Surgery on the 3rd of April 2009.

Clinical Trial Registration: This clinical trial is registered on Clinical Trials: http://www.clinicaltrials.gov/.

Trial registry name: The DIEP-flap as a model of ischemia-reperfusion.

Registration identification number (NCT): 00482469.

Reprints: Marieke G. W. van den Heuvel, MD, Department of Plastic, Reconstructive and Hand Surgery, Maastricht University Medical Centre, PO Box 5800-6202 AZ, Maastricht, The Netherlands. E-mail: m.vandenheuvel@AH.unimaas.nl.

Copyright (C) 2011 by Lippincott Williams \& Wilkins

ISSN: 0148-7043/11/6606-0648

DOI: $10.1097 /$ SAP.0b013e3181e37bc8

\section{THE LASER DOPPLER IMAGER}

Flow measurements in free flaps have been performed before by LDF. This method, however, uses only 1 or 2 reference points. LDF probes measure a surface area of $1 \mathrm{~mm}^{2}{ }^{3}$ The laser Doppler imager (LDI) offers the possibility to evaluate blood flow in a larger area or the entire free flap instead of 1 small reference point. Using software, statistical analyses can be performed. The technique is based on an infrared laser that measures full dermal thickness, with a penetration depth of around $2 \mathrm{~mm}$. Red blood cells floating through cutaneous capillaries change the direction of the reflected infrared light. ${ }^{4}$ Through the change in angle of the light, the LDI can calculate relative flux values (blood flow/time unit), expressed as perfusion units. ${ }^{4}$ Every LDI scan pixel represents a single flux measurement.

The purpose of this study is to measure the pattern of perfusion of free flaps during the process of transplantation, using the DIEP flap as a model and the LDI as flow measuring method.

\section{MATERIALS AND METHODS}

\section{Population}

We studied 16 flaps in 14 DIEP patients undergoing secondary breast reconstruction at the Department of Plastic and Reconstructive Surgery in the Maastricht University Medical Centre in The Netherlands. Two patients underwent bilateral surgery. The population consisted of women who had undergone breast amputation or mastectomy due to breast cancer or to prevent breast cancer. A written informed consent procedure was followed.

Inclusion criteria were an indication for secondary DIEP breast reconstruction, unilateral as well as bilateral, and age of 18 years or older. Exclusion criteria were a medical history of diabetes mellitus, diseases of the kidneys or liver, or the use of immunosuppressants. The study was conducted according to the principles of the Declaration of Helsinki (fifth version, July 24, 2001) and in accordance with the Medical Research Involving Human Subjects Act (Wet Medisch Weteschappelijk Onderzoek met mensen [WMO]) approved by the Ethical Committee of Maastricht University Medical Centre.

\section{Structure of the Experiment}

With the use of the LDI, the perfusion of the flap was measured at 4 different time points-before, during, and after the DIEP operation.

- One day preoperatively;

- Peroperatively, when the flap was supplied by the abdominal vascular pedicle only;

- Immediately postoperatively;

- Twenty-four hours after reperfusion.

The first measurement was performed before surgery to serve as a reference for the patient's tissue perfusion (baseline measurement). This measurement was done at a part of the abdomen that would ultimately become the free flap. The following measurement was performed peroperatively, when the flap was dissected free and supplied by the abdominal vascular pedicle only. At this point, the perfu- 
sion pattern of the flap changes. Next, blood flow through the free flap was measured directly postoperatively and 24 hours after reperfusion to see whether perfusion of the free flap changed. Following baseline values possibly intervening with the main study parameters (confounders) were registered: body mass index, smoking, previous radiotherapy, operative time, duration of ischemia, flap weight, anesthesia, temperature, total volume of replaced volume, tension, and pulse (Tables 1 and 2).

\section{LDI Measurements}

LDI measurements were performed with the LDI2-IR near infrared imager (Moor Instruments Ltd, Devon, United Kingdom) using an infrared laser beam and a high resolution continuous scan

\section{TABLE 1. Baseline Values}

\begin{tabular}{lc}
\hline Time Point & \multicolumn{1}{c}{ Baseline Values } \\
\hline Preoperative & BMI, smoking, previous radiotherapy \\
Peroperative & $\begin{array}{c}\text { Operative time, duration of ischemia, flap weight, } \\
\text { tension, and pulse during biopsies }\end{array}$ \\
\hline
\end{tabular}

Baseline values that were integrated included as covariates in statistical analysis. In the end, only those values that showed significant association $(P \leq 0.05)$ with flux values were included in the linear mixed models analysis (see result section).

BMI indicates body mass index.

\section{TABLE 2. Population Characteristics}

\begin{tabular}{lrr}
\hline & Mean & SD \\
\hline Age $(\mathrm{yr})$ & 49.3 & 8.97 \\
BMI $\left(\mathrm{kg} / \mathrm{m}^{2}\right)$ & 26.9 & 3.32 \\
Duration surgery (min) & 505.9 & 138.78 \\
Duration ischemia (min) & 78.9 & 17.81 \\
Flap weight $(\mathrm{g})$ & 656.6 & 204.97 \\
\hline
\end{tabular}

Demographic variables of the study population represented as means and standard deviations (SD).

BMI indicates body mass index. mode. During all LDI scans, patients were positioned on their backs Eye protection glasses provided by Moor Instruments were used. The LDI measured a standardized marked flap area of $10 \mathrm{~cm}$ high $\times$ $15 \mathrm{~cm}$ wide, which was preoperatively drawn down from the umbilicus along the vertical midline of the abdomen (Fig. 1). A square of $2 \times 2 \mathrm{~cm}$ was drawn onto the flap to be used as a scale for analyzing measurements. With all scans, the same area was measured (Fig. 2). Preoperatively, both the left and right half of the abdomen were measured. During surgery, it was determined which half of the abdomen would be used as a free flap.

\section{Calculations and Statistics}

In every scan, 2 squares of $2 \times 2 \mathrm{~cm}$ were selected for analysis. One square above the perforator, to determine blood flow in the central part of the free flap, and another one above the lateral border of the free flap to measure peripheral blood flow in the free flap. Every scan pixel represents a flux measurement, which correlates with the intensity of the blood flow. Of every square, the mean flux and the standard deviation are calculated by the Moor software.

For every time point, central (perforator) and peripheral flux measurements were compared using an unpaired, 2-tailed student $t$ test. For evaluation of central and peripheral blood flow measurements over time, statistical analysis by SPSS linear mixed models has been performed. ${ }^{5}$ This analysis corrects for dependency of repeated measurements. Flux values were compared with the same person's concentrations preoperatively on the ipsilateral part of the abdomen. Baseline values of patient and operation characteristics were included integrated as covariates. Statistical correction has taken place for patients who underwent bilateral DIEP surgery. Significance was considered present at $P \leq 0.05$.

\section{RESULTS}

Out of 16 free flaps, 1 showed a hematoma and clinical signs of venous congestion on the first postoperative day. Salvage surgery was immediately performed. The directly postoperative LDI value of this patient was not deviant. The last LDI measurement was performed directly after salvage surgery the next day, and the

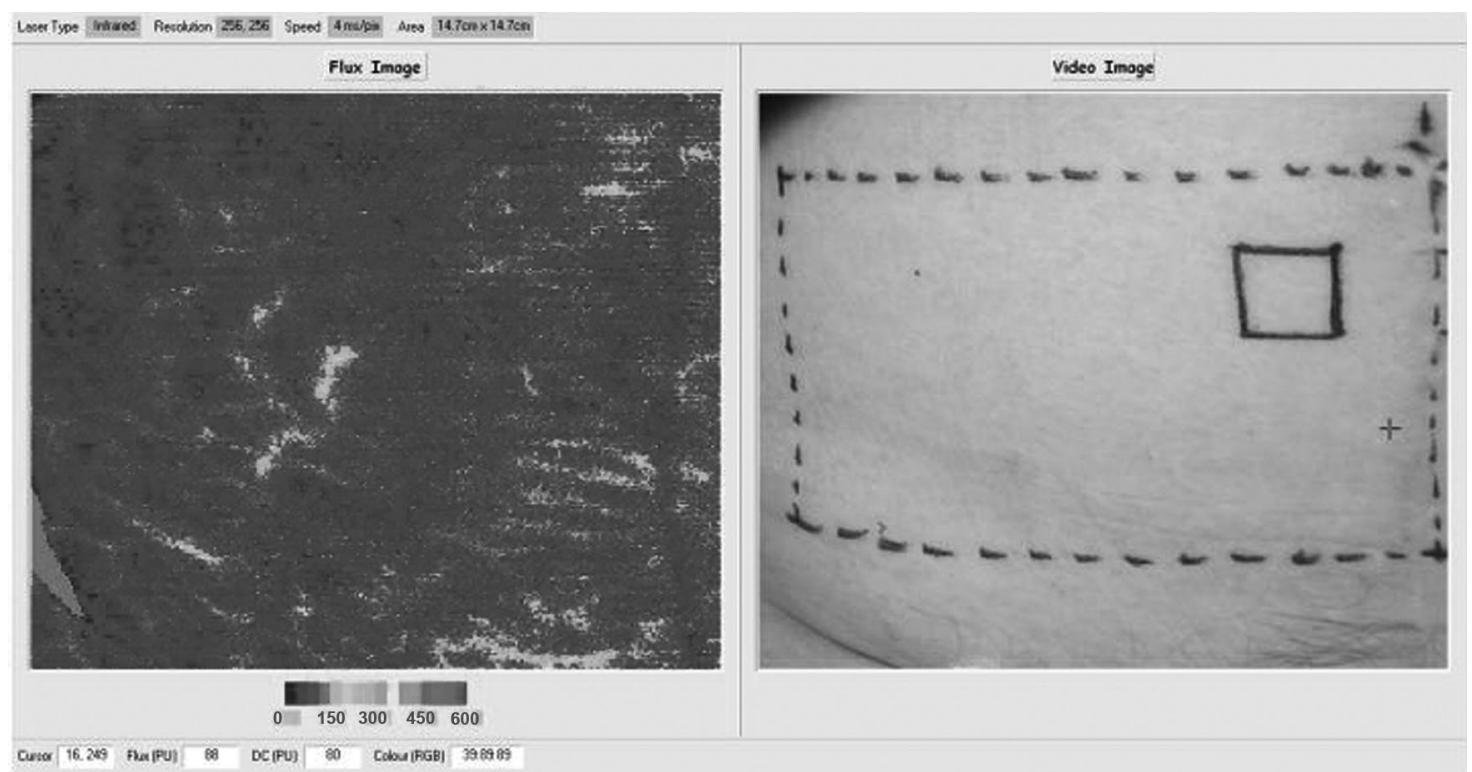

FIGURE 1. Preoperative LDI measurement. For the preoperative LDI scan, a marked flap area of $10 \mathrm{~cm}$ high $\times 15 \mathrm{~cm}$ wide was preoperatively drawn down from the umbilicus along the vertical midline of the abdomen. A square of $2 \times 2 \mathrm{~cm}$ was drawn onto the flap to be used as a scale for analyzing measurements. 


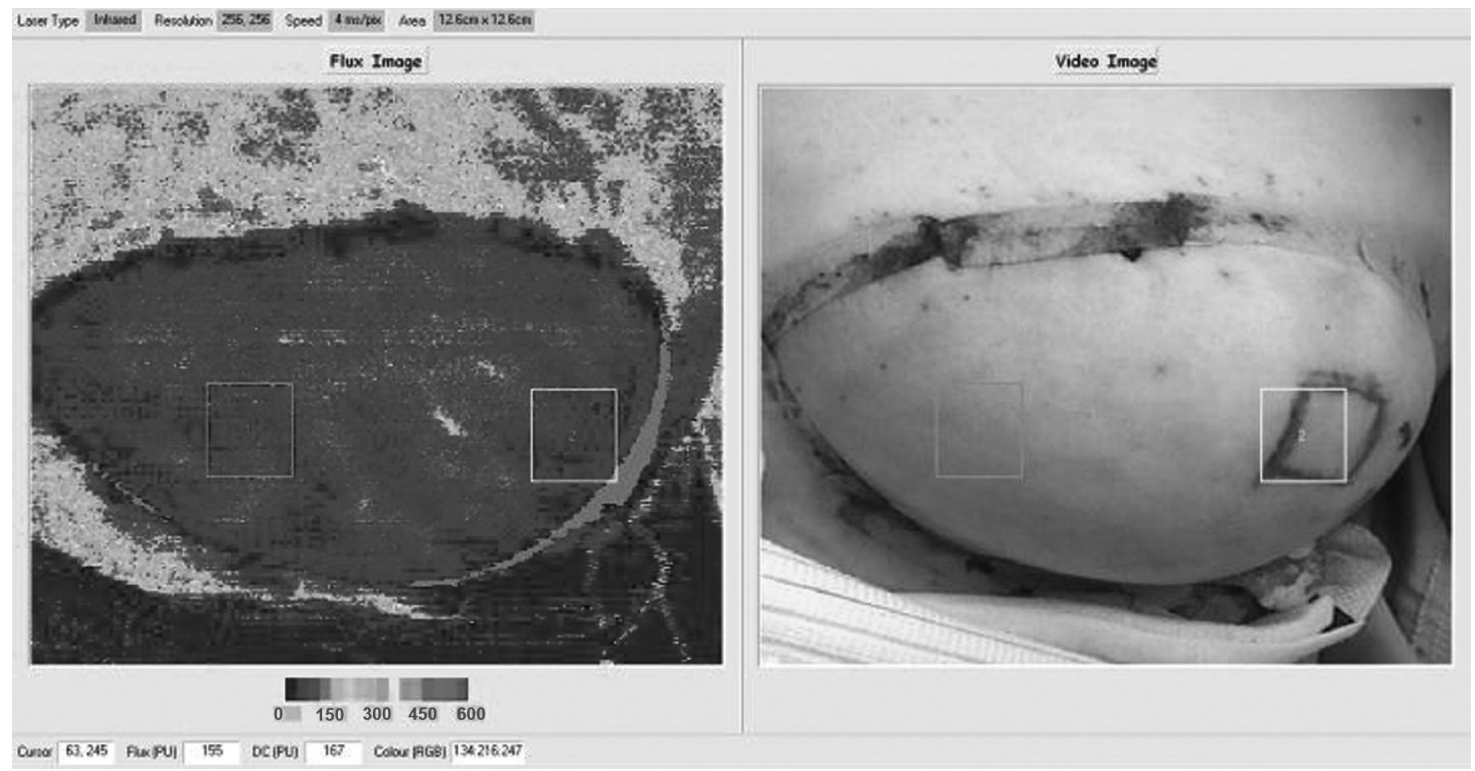

FIGURE 2. LDI measurement 24 hours postreperfusion. A LDI scan 24 hours postreperfusion. The day before surgery, a square of $2 \times 2 \mathrm{~cm}$ was drawn onto the flap to be used as a scale for analyzing measurements. Therefore, in all scans the same area could be measured for statistical analysis.

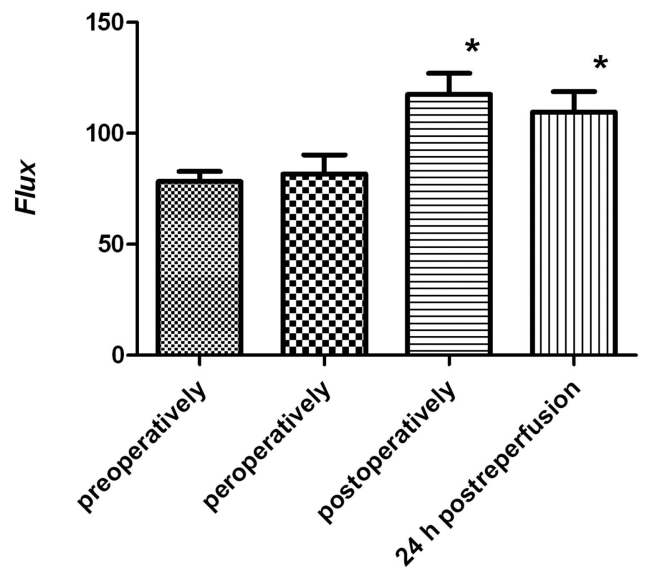

FIGURE 3. Flux values above the perforator. Mean flux values \pm SEM measured by laser Doppler imager above the perforator of the free flap. Measurements were performed preoperatively, peroperatively when the flap was still supplied by the vascular pedicle, directly postoperatively, and 24 hours postreperfusion. Blood flow values postoperatively and 24 hours postreperfusion were significantly higher than the pre- and peroperative measurements (significance is marked by an asterisk).

peripheral flux value declined from normal to borderline low. Unfortunately, the eventual development of partial flap necrosis could not be prevented in this patient (about 33\%, the lateral part of the flap). All the other free flaps displayed no complications postoperatively. Flux values were measured (Figs. 3, 4, Table 3) and compared with baseline measurement or measurements at other time points. $P$ values are shown in Tables 4 and 5 .

\section{Central Compared With Peripheral Blood Flow}

Preoperatively and peroperatively (the flap is still supplied by the vascular pedicle), there is no difference between blood flow in

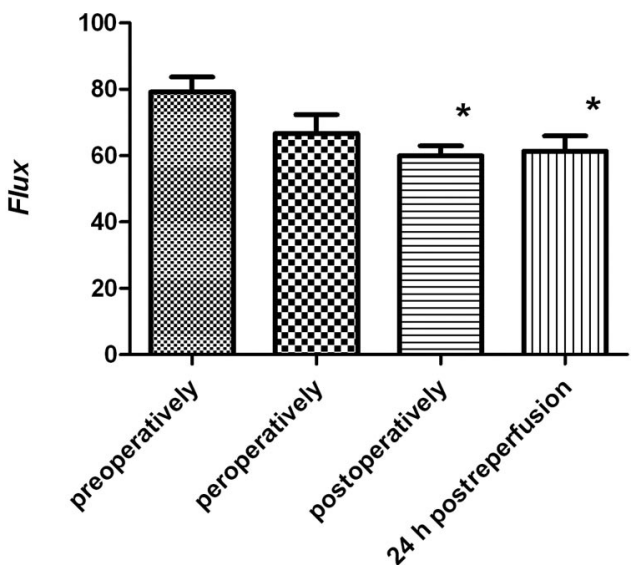

FIGURE 4. Distal flux values. Mean flux values \pm SEM measured by laser Doppler imager in the distal part of the free flap. Measurements were performed preoperatively, peroperatively when the flap was still supplied by the vascular pedicle, directly postoperatively, and 24 hours postreperfusion. Blood flow values postoperatively and 24 hours postreperfusion were significantly lower than the preoperative measurements (significance is marked by an asterisk).

the central and the peripheral parts of the flap $(P=0.884$ and $P=$ 0.160 , respectively). Remarkably, the pattern of blood flow changes after transplantation of the flap to the thorax. Directly after surgery and 24 hours after reperfusion, blood flow is significantly higher in the central part of the free flap, compared with the peripheral border $(P=0.000$, twice $)$.

\section{Blood Flow in the Flap Part Surrounding the Perforator}

Remarkably, blood flow through the flap did not alter significantly after dissection, when blood supply became restricted to the abdominal vascular pedicle only. After transplantation of the flap 
TABLE 3. Flux Measurements

\begin{tabular}{|c|c|c|c|c|}
\hline Time Point & $\begin{array}{c}\text { Flux } \\
\text { Anastomosis }\end{array}$ & $\begin{array}{c}\text { Pixel } \\
\text { Validity } \\
\text { Anastomosis } \\
(\%)\end{array}$ & Flux Distal & $\begin{array}{c}\text { Pixel } \\
\text { Validity } \\
\text { Distal } \\
(\%)\end{array}$ \\
\hline Preoperatively & $78.3 \pm 4.61$ & 100.0 & $79.2 \pm 4.65$ & 100.0 \\
\hline Peroperatively & $81.7 \pm 8.98$ & 100.0 & $66.7 \pm 5.91$ & 100.0 \\
\hline Postoperatively & $117.5 \pm 9.85$ & 99.8 & $60.0 \pm 3.06$ & 99.8 \\
\hline $24 \mathrm{~h}$ postoperatively & $109.5 \pm 9.52$ & 99.9 & $61.4 \pm 4.73$ & 100.0 \\
\hline
\end{tabular}

Flux values (means \pm SEM) measured above the perforator or in the peripheral (distal) part of the flap at different time points. Flux values are relative (blood flow/time unit) and expressed as perfusion units (PU). Of every measurement the number of valid scan pixels is displayed. In a scan, every pixel represents a flow measurement.

TABLE 4. $\quad P$ of Comparison Between Flux Measurements Above the Perforator of the Free Flap

$24 \mathrm{~h}$

Preoperative Peroperative Postoperative Postoperative

\begin{tabular}{lcccc}
\hline Preoperative & - & 0.728 & $0.001 \uparrow$ & $0.005 \uparrow$ \\
Peroperative & 0.728 & - & $0.008 \uparrow$ & $0.033 \uparrow$ \\
Postoperative & $0.001 \downarrow$ & $0.008 \downarrow$ & - & 0.530 \\
$24 \mathrm{~h}$ & $0.005 \downarrow$ & $0.033 \downarrow$ & 0.530 & - \\
$\quad$ postoperative & & & &
\end{tabular}

$P$ of comparison between flux measurements (blood flow/time unit) in the free flap above the perforator. The arrows indicate whether the flux measurements noted in columns were higher (arrow up) or lower (arrow down) compared to the measurements noted in rows (in the left of the table). Statistical analysis was performed using SPSS linear mixed models. Significance was considered present at $P \leq 0.05$.

TABLE 5. $P$ of Comparison Between Flux Measurements in the Peripheral Part of the Free Flap

$24 \mathrm{~h}$

Preoperative Peroperative Postoperative Postoperative

\begin{tabular}{|c|c|c|c|c|}
\hline Preoperative & - & 0.073 & $0.001 \downarrow$ & $0.006 \downarrow$ \\
\hline Peroperative & 0.073 & - & 0.271 & 0.419 \\
\hline Postoperative & $0.001 \uparrow$ & 0.271 & - & 0.778 \\
\hline $\begin{array}{l}24 \mathrm{~h} \\
\quad \text { postoperative }\end{array}$ & $0.006 \uparrow$ & 0.419 & 0.778 & - \\
\hline
\end{tabular}

$P$ of comparison between flux measurements (blood flow/time unit) in the peripheral part of the free flap. The arrows indicate whether the flux measurements noted in columns were higher (arrow up) or lower (arrow down) compared to the measurements noted in rows (in the left of the table). Statistical analysis was performed using SPSS linear mixed models. Significance was considered present at $P \leq 0.05$.

(the postoperative and 24 hours postreperfusion measurement), blood flow in the central part of the flap became significantly higher compared with the blood flow values before surgery and during surgery when the flap was still supplied by the vascular pedicle. There was no difference between blood flow directly after surgery and 24 hours postreperfusion.

\section{Blood Flow in the Peripheral Part of the Flap}

Also in the peripheral part of the free flap, blood flow did not alter significantly after the flap was dissected free and was supplied by the vascular pedicle only. Blood flow in the peripheral part of the flap showed a significant decrease after transplantation of the flap (measurements directly postoperative and 24 hours postreperfusion), compared with blood flow values before surgery. Flow values directly after surgery and 24 hours after reperfusion were comparable.

\section{Relation to Baseline Characteristics}

Some patient demographics and operation characteristics were included in statistical analysis as covariates, which are as follows: body mass index, smoking, previous radiotherapy, operative time, duration of ischemia, flap weight, tension, and pulse. There were no significant relations between blood flow values above the perforator and one of the covariates. There was only one smoker, and this patient displayed a significantly lower peripheral blood flow than nonsmokers.

\section{DISCUSSION}

Before surgery and transplantation of the flap, there are no differences between the central and peripheral blood flow pattern in the flap. However, directly after surgery and 24 hours after reperfusion, blood flow is significantly higher in the central part of the free flap compared with the peripheral border. This is as expected, because after transplantation of the flap to the thorax, blood flow becomes restricted to 1 central artery and vein.

The finding that after transplantation, blood flow was higher in the central part of the flap than in the peripheral zone, matches the outcome of measurements over time. It was demonstrated that blood flow in the central part of the flap increased significantly postoperatively and 24 hours postreperfusion. This relative hyperperfusion is according to the earlier observations. Although Figus et al showed an initial decrease in light-guide reflectance spectrophotometry values in DIEP flaps, blood flow subsequently recovered to presurgical levels after 12 to 16 hours. ${ }^{3}$ They also monitored DIEP flaps with LDF, showing a significantly inclined postoperative blood flow. Yoshino et al also demonstrated a temporary decrease in blood flow after flap transplantation. ${ }^{2}$ However, this recovered immediately after reconstruction and even continued to increase until the second postoperative day. ${ }^{2}$ Heitland et al measured blood flow in donor vessels and the anastomosed pedicles of DIEP patients using Duplex ultrasonography, and this study also demonstrated flap hyperperfusion 5 days and 18 months postoperatively. ${ }^{6}$ de Weerd et al performed dynamic infrared thermography on DIEP flaps and found that perfusion of the free flap is a stepwise process featured by hyperemia, during which the subdermal plexus of the whole flap is adequately perfused. The subcutaneous tissue, however, is only well perfused after several days, when the choke vessels in this layer have dilated. ${ }^{7}$

Despite an initial decrease in blood flow levels in some studies, all studies eventually demonstrated a relative hyperperfusion of free flaps postoperatively, confirming our results. There are several possible explanations for this observation. Capillary flow can increase because, after dissection, perfusion of the flap is based on a single perforator compared with the preoperative condition where multiple perforators supply the flap. ${ }^{3}$ Consequently, a large vessel flow is forced through a smaller caliber perforator vessel, resulting in a relatively increased perfusion. ${ }^{3}$ Other explanations may be an increased cardiac output as a result of the surgical procedure, declined vascular resistance due to sympathetic denervation or a compensation mechanism for higher oxygen consumption in the transplanted tissue. ${ }^{7,8}$

In the peripheral part of the flap, there was a decrease in blood flow directly after surgery and 24 hours after reperfusion, compared with baseline flow values. This was expected, because it is known that the peripheral zone of the flap has a higher chance of necrosis. Blood supply to the tissue flap changes after transplantation and new collaterals need to be formed. For that reason, blood flow in the peripheral part of the flap was expected to decrease after transplan- 
tation of the flap. Our findings are in line with previous literature. LDF measurements in different zones of DIEP flaps demonstrated that flow decreased the farther the zone was located from the source pedicle. ${ }^{1}$ Hallock and Rice performed DIEP flaps in rats and found the highest blood flow near the anastomosis and a significantly lower blood flow in the peripheral part of the flaps. ${ }^{1,9}$ A patient study from Booi et al also demonstrated a significantly lower blood flow in zone IV of the free flap compared with zone I, with a strong increase on the second to third postoperative day. ${ }^{10}$ It is important to realize that most other studies consider zone IV the peripheral part of the flap, while in our experiment zone II represents the lateral border of the flap. Our surgeons routinely discard zone IV of the free flap to reduce the chance of complications. This accounts especially for DIEP flaps, where blood flow is lower compared with transverse rectus abdominus myocutaneous flaps, which are supplied by multiple perforators. ${ }^{6}$ Flow rates are significantly lower in zone IV than in zone II, ${ }^{1}$ otherwise an even lower blood flow would have been measured in that area. In a study of Holm et al, perfusion of zone IV was completely absent in $33 \%$ of the patients and dramatically low in $5 \% .{ }^{11}$

Surprisingly, blood flow through the flap did not change significantly when blood supply to the flap became restricted to 1 perforating artery and vein. This accounted for the central and the peripheral parts of the flap. A significant change in blood flow occurred only after transplantation of the flap to the thorax. A possible explanation is that adaptation to the new situation takes some time, and therefore no immediate change in flow can be measured.

During the experiment, important operation characteristics like operative time, duration of ischemia, flap weight, anesthesia, temperature, total volume of replaced volume, tension and pulse were recorded. Because some measurements were performed in the operating room when the patient was under anesthesia and others were not, environmental factors could influence perfusion measurements. To compensate for that, some patient and operation characteristics that could influence perfusion were integrated in statistical analysis as a covariate. Since most environmental factors like anesthesia, temperature, replaced fluid, etcetera, influence blood flow through a change in pulse or tension, these last 2 variables were also integrated in statistical analysis as a covariate. However, except for smoking, none of the covariates significantly influenced the outcomes. Consequently, environmental factors, except smoking, did not significantly influence perfusion. According to expectations, LDI measurements demonstrated that the 1 smoker in our study displayed a significantly lower blood flow in the peripheral part of the flap than nonsmokers. This was already a common thought based on a rat study. ${ }^{12}$ These results also confirm the findings of Booi et al. ${ }^{13}$ On the contrary, central blood flow is not impaired by smoking.

In this study, measurement localizations are referred to as "central" and "peripheral." We have decided not to refer to Hartrampf zones of perfusion, because the boundaries between those zones are arbitrary, and this concept is discussed nowadays. Hartrampf perfusion zones of the abdominal flap divide the flap into 4 equal parts where perfusion declines with increasing zone number. This indicates that perfusion of the contralateral adjacent zone would be higher than that of the adjacent zone on the same side as the perforant. However, Holm et al demonstrated that the opposite is true. After DIEP surgery, zone III is perfused faster and more intensely than zone II because of a poor vascular cross-linking over the abdominal midline. ${ }^{11}$ This confirms an earlier study of Blondeel et al, discussed in Holm et $\mathrm{al}^{11}$ where they demonstrated that branches crossing the midline were much less frequent and of smaller caliber. Wong et al also found that vascular territories prefer to remain on the ipsilateral half of the abdomen. ${ }^{14}$ Furthermore, they demonstrated that perfusion of a free flap is dependent on the location of the perforator. ${ }^{14}$ If a medial perforator is used, zone II is perfused faster and more intensely than zone III. If, however, a lateral perforator is used, it is the other way around. ${ }^{14}$

Until now, other studies only investigated blood flow using a single probe. Therefore, flow is only measured at 1 point, which in most studies was random or a combination of a central and a peripheral measurement point. However, blood flow values in tissue are very variable. For example, if a measurement is done directly above the blood vessel, a high flow will be found. On the contrary, flow measurements in between blood vessels may be much lower. Therefore, single point measurements are less reliable. The advantage of the LDI compared with other methods for flow measurement, is that a larger tissue area can be measured. Calculating an average flux value is a more reliable method. Through this, the LDI overcomes the flaws of the single point measurement. This study proves that the LDI is a useful instrument for perfusion measurements. It could, for instance, be an appropriate tool for demonstrating the effect of a certain drug on blood flow.

In our study, 1 patient showed a hematoma and venous congestion on the first postoperative day. The postoperative LDI value of this patient was not deviant. Although at that time the flap displayed no clinical signs of flap failure, the LDI measurement could not forecast the troubles ahead. On the first postoperative day, salvage surgery was performed and directly after that the last LDI measurement took place. The peripheral flux value did show a fall in flux value; however, salvage surgery had already occurred. This example clearly illustrates that the LDI is not a suitable device for free flap monitoring. Measurements are not performed continuously, but with time intervals, and they can not predict flap survival.

In conclusion, LDI measurements demonstrated that the pattern of blood flow in a free flap changes after transplantation, when blood flow is significantly higher in the central part of the free flap compared with the peripheral border. In the central part of the flap, blood flow significantly increased postoperatively and 24 hours after reperfusion, compared with blood flow values before and during surgery. Blood flow in the peripheral part of the flap, however, demonstrated a decrease directly after surgery and 24 hours postreperfusion. Remarkably, both in the central and the peripheral parts of the flap, blood flow did not alter significantly after dissection, when the flap is supplied by the abdominal vascular pedicle only.

\section{REFERENCES}

1. Hallock GG. Physiological studies using laser Doppler flowmetry to compare blood flow to the zones of the free TRAM flap. Ann Plast Surg. 2001;47: $229-233$.

2. Yoshino K, Nara S, Endo M, et al. Intraoral free flap monitoring with a laser Doppler flowmeter. Microsurgery. 1996;17:337-340.

3. Figus A, Mosahebi A, Ramakrishnan V. Microcirculation in DIEP flaps: a study of the haemodynamics using laser Doppler flowmetry and lightguide reflectance spectrophotometry. J Plast Reconstr Aesthet Surg. 2006;59:604612; discussion 613

4. Huang X, Lu L, Gush RJ, et al. A new, fast, high resolution laser Doppler imager for clinical and research use. Sixth world congress for microcirculation. Publisher: Monduzzi Editore SpA, Bologna, Italy. 1996.

5. Verbeke G, Molenberghs G. Linear Mixed Models for Longitudinal Data. New York, NY: Springer; 2000

6. Heitland AS, Markowicz M, Koellensperger E, et al. Duplex ultrasound imaging in free transverse rectus abdominis muscle, deep inferior epigastric artery perforator, and superior gluteal artery perforator flaps: early and long-term comparison of perfusion changes in free flaps following breast reconstruction. Ann Plast Surg. 2005;55:117-121.

7. de Weerd L, Miland AO, Mercer JB. Perfusion dynamics of free DIEP and SIEA flaps during the first postoperative week monitored with dynamic infrared thermography. Ann Plast Surg. 2009;62:42-47.

8. Holzle F, Loeffelbein DJ, Nolte D, et al. Free flap monitoring using simul- 
taneous non-invasive laser Doppler flowmetry and tissue spectrophotometry. J Craniomaxillofac Surg. 2006;34:25-33.

9. Hallock GG, Rice DC. Comparison of TRAM and DIEP flap physiology in a rat model. Plast Reconstr Surg. 2004;114:1179-1184.

10. Booi DI, Debats IB, Boeckx WD, et al. A study of perfusion of the distal free-TRAM flap using laser Doppler flowmetry. $J$ Plast Reconstr Aesthet Surg. 2008;61:282-288.

11. Holm C, Mayr M, Hofter E, et al. Perfusion zones of the DIEP flap revisited: a clinical study. Plast Reconstr Surg. 2006;117:37-43.
12. van Adrichem LN, Hoegen R, Hovius SE, et al. The effect of cigarette smoking on the survival of free vascularized and pedicled epigastric flaps in the rat. Plast Reconstr Surg. 1996;97:86-96.

13. Booi DI, Debats IB, Boeckx WD, et al. Risk factors and blood flow in the free transverse rectus abdominis (TRAM) flap: smoking and high flap weight impair the free TRAM flap microcirculation. Ann Plast Surg. 2007;59:364-371.

14. Wong C, Saint-Cyr M, Arbique G, et al. Three- and four-dimensional computed tomography angiographic studies of commonly used abdominal flaps in breast reconstruction. Plast Reconstr Surg. 2009;124:18-27. 